\title{
An Intertextual Perspective of the Strategies of Composing Images in American Imagist Poetry and Chinese Tang Poetry
}

\author{
Ying-jie Guo \\ School of Foreign Languages, Shaanxi Normal University, Xi'an 710062, China \\ guoyingjie@snnu.edu.cn
}

Keywords: Intertextualité, strategies, images, American Imagist Poetry, Chinese Tang Poetry.

\begin{abstract}
To examine the strategies of composing images in American Imagist Poetry and Chinese Tang Poetry, this paper employs Julia Kristeva's theory of intertextualite and conducts a comparative study. In the intertextual perspective, the paper holds that American Imagist Poetry and Chinese Tang Poetry share certain intertextual qualities though they have distinctive cultural systems. The conclusions include that both emphasize the direct and objective treatment of the images, advocate the compact and masculine language, and highlight the musical rythmes while pouring out emotions. The originality of the paper is that an intertextual methodology has been introduced into the comparative study of American Imagist Poetry and Chinese Tang Poetry.
\end{abstract}

\section{Introduction}

Nowadays, "intertextualité" is a well-known term in the literary world and its English form is "intertextuality". It is Julia Kristeva(1941- ), a distinguished Bulgarian-French critic, who has coined "intertextualité" and made it recognized initially in 'Word, Dialogue and Novel'(1966), and then in 'The Bounded Text"(1966-67). According to Kristeva, "any text is constructed as a mosaic of quotations; any text is the absorption and transformation of another'"[1]. So to speak, any text, including the literary word, will be the inter-section of other texts "where at least one other word(text) can be read". Meanwhile, any text can not exist as a self-contained system, and it can not function as a self-sufficient unit. To put it concrete, any text will be "the absorption and transformation of another" and may establish close relationship with "other texts" through the devices of allusion, collage, quotation, translation, immitation, reference, fusion, parody, etc. Besides Kristeva's illustration of "intertextualité", there is another French citic named Tiphaine Samoyault(1968- ), who also contributes to the sophisticated intertexutal theory, declares in his L'Intertextualité: Mémoire de la Littérature(2001) that literature as a demonstration of text "comes out when negotiating with its outside world, and get accomplished when communicating with itself and its history," "texts are innately distinctive in nature, yet in principle, they are dependent, echoing and interactive"[2]. Based upon the knowledge above, both American Imagist Poetry and Chinese Tang Poetry are the excellent instances of the texts of human civilizations, and they are the literary results of the corresponding cultures as well. Moreover, although the two poetic systems are different, as texts, they may share certain qualities and features in nature. To be more specific, both American Imagist Poetry and Chinese Tang Poetry are the heritages of their respective cultures, thus as the particular historical beings, the two texts can be intertextual, communicative and interactive.

Probing into the poetic texts, readers may find colorful contents that characterize the intertextual features of the two. Among other things, the strategies of composing images in American Imagist Poetry and Chinese Tang Poetry will be one of the striking themes. In essence, though American Imagist Poetry and Chinese Tang Poetry are superficially distinctive, they do share certain intertextual qualities within their own cultural systems.

\section{Strategies of Composing Images in American Imagist Poetry and Chinese Tang Poetry}

Both Emphasize the Direct and Objective Treatment of the Images. Ezra Pound(1885-1973), the spokesman of American Imagist Poetry, proclaimed publicly in "A Retrospect"(1918) that it was urgent and basically crucial for modern poets to treat the poetic "thing" or "image" directly while writing poetry, "whether 
subjective or objective"[3]. Pound's thought transparently echoed that of F. S. Flint(1885-1960), a British Imagist at that time who also meant to popularize the poetry of hardness, clarity and restraint. But by contrast, Pound seemed more daring and revolutionary. Most important of all, Pound practiced his imagist thoughts in poetry writing and made his principle observed. Here comes a typical example, "The apparition of these faces in the crowd:/ Petals on a wet, black bough." It is Pound's most frequently quoted poem titled "In a Station of the Metro". This poem was said to be composed in 1914 after Pound obtained unexpected inspirations while he was waiting for a metro in Paris. Originally, to restore and construct the scene he encountered in 1913, Pound wrote thirty lines. However, he was not satisfied at all. Several months later, he wrote the poem again, fifiteen lines altogether. But Pound was still unsatisfied. After a period of speculation and refinement, he composed just two lines, as is shown above, and the two-line poem became a monumental masterpiece. Frankly speaking, one of the successful strategies that Pound employed is that he undertook the direct and objective treatment of the images he saw and imagined between the poetic lines. Specifically, in the first line, "these faces in the crowd" are the realistic images whereas "the crowd" serves as the background of "these faces". Obviously, the first line is a portrayal of reality. While in the second line, "Petals on a wet, black bough" is full of imagined images and "a wet, black bough" acts as the setting of "petals". In brief, the second line is a representation of Pound's unique imagination, from which readers can see how great Pound was in dealing with the poetic images. Besides Pound's work, there is another example of this kind, a poem titled "The Red Wheelbarrow" by William Carlos Williams(1883-1963)-“so much depends/ upon/ a red wheel/ barrow/ glazed with rain/ water/ beside the white/ chickens"[4]. In this poem, Williams also brilliantly had direct and objective treatment of such images as "a red wheel", "barrow", "rain", "water", "the white/ chickens", etc to display the unusual feelings he harvested in an usual atmosphere, revealing a truth that there is no shartage of beauty in our life but short of the eye to find the beauty around us.

In Chinese Tang Poetry, Tang Poets had developed the custom of using images acutely, adopting direct writing policy for images and having objective treatment of images when composing poetic lines. Among the outstanding Tang Poets, He Zhizhang(659-744), Wang Zhihuan(688-742), Meng Haoran(689-740), Wang Changling(698-757), Wei Yingwu(737-792), Liu Yuxi(772-842), Meng Jiao(751-814), Han Yu(768-824), Liu Zongyuan(773-819), Li Bai(701-762), Du Fu(712-770), Du Mu(803-852), Li Shangyin(813-858), etc are just a few of the representatives. All Tang Poets had taken serious but artisitc attitudes towards images either in reality or in imagination. And the striking feature is that Tang Poets would like to integrate their complicated feelings and desires into the practicalemployment of various images. To illustrate this point, let us read some examples. Wang Changling ever accomplished a poem titled "Army Life"-"Clouds on frontier have darkened mountains clad in snow; / The town with Gate of Jade stands far away, forlorn./ We will not leave the desert till we beat the foe,/ Although in war our golden armour be outworn."[5] In this poem, Wang Changling successfully referred to many striking images like "clouds on frontier", "mountains", "snow", "town", "Gate of Jade", "desert", "foe", "war", "golden armour", etc to demonstrate the meanness of the living conditions of the soldiers on frontier, which becomes a good contrast to show how optimistic the soldiers were when confronting difficulties and danger in war. Besides, Liu Yuxi's "The Street of Mansions" is another master work to prove that Tang Poets were good at using direct and objective images in their writing- "Beside the Bridge of Birds rank grasses overgrow;/ Over the Mansion Street the setting sun hangs low./Swallows that skimmed by painted eaves in bygone days/ Are dipping now among the humble homes' doorways."[5] This poem was successfully written because such images as "Bridge of Birds", "the Mansion Street", "Swallows", "painted eaves", etc are the results of Liu Yuxi's direct and objective treatment of the glorious past of a dynasty and then revealed his personal pondering and pities about the changes of "today" by portraying the images like "grasses", "the Street", "the setting sun", "bygone days", etc.

Both Advocate the Compact and Masculine Language. American Imagist Poetry is essentially a revolt against the conventional Victorian poetic trend that, particularly in the later period, characterized itself with elegant, luxurious and sentimental expressions. And of course, the language and style in the Late Victorian Age were gaudy and magniloquent. The Imagsits like Pound, H. D. (Hilda Doolittle, 1886-1961), Richard 
Aldington (1891-1962), Amy Lowell (1874-1925), John Gould Fletcher (1886-1950), Joseph Campbell (1879-1944), D. H. Lawrence (1885-1930), etc felt disdained at the poetic dacadence and attempted to initiate experimental changes in a variety of poetic categories, one of which was the very form of language. As for them, the poetic language should be compact, masculine and full of vigor, at least different from the Victorian frothy and effeminate tone. To do so, the Imagist poets like H.D. stood out and made enterprising revolutions. H.D.'s work titled “Oread" can be viewed as a representative one of this sort-“Whirl up, sea-/ Whirl your pointed pines/Splash your great pines/ On our rocks/ Hurl your green over us/ Cover us with your pools of fur". In this poem, H.D. did not behave sentimentally even though she was a lady and had thousands of excuses to act coquettishly. Transparently, H.D. maintained an avant-garde attitude and believed that the charm of the language lies in its masculine aspects. Her poetic images like "sea", "pointed pines", "rocks", "your green", "pools of fur", etc turned out to be the evidences to show they were distinctive from Victorian tradition. What's more, the verbs like "whirp up", "splash", "hurl", "cover", etc demonstrated the masculine power of the author through the accumulated utterance. Apart from H.D.'s "Oread", Richard Aldington's "Round-Pond" serves as another instance-"Water ruffled and speckled by galloping wind/ Which puffs and spurts it into tiny pashing breakers/ Dashed with lemon-yellow afternoon sunlight./ The shining of the sun upon the water/ Is like a scattering of gold crocus-petals/ In a long wavering irregular flight./ The water is cold to the eye/ As the wind to the cheek./ ...'[4] Obviously, such extraordinary images as "water", "wind", "breakers", "sunlight", "sun", "crocus-petals", "eye", "cheek", etc were compact and unusual in expression. Once with the foil of the verbs like "ruffled and speckled", "galloping", "puffs and spurts", "pashing", etc, the images mentioned above were more impressive as they filled themselves with masculine energy and strength.

In Chinese Tang Poetry, Tang Poets also paid much attention to the conciseness and masculinity of language. On the one hand, Tang Poets wanted to make a big difference in the poetic world, especially attempting to break away from the declining poetic traditions cultivated in the Liang Dynasty(502-557) and Sui Dynasty(581-618). Li Bai ever wrote a poem titled "Invitation to Wine" and it reads-"Do you not see the Yellow River come from the sky,/ Rushing into the sea and ne'er come back?/ Do you not see the mirrors bright in chambers high/ Grieve o'er your snow-white hair though once it was silk-black?/ When hopes are won, oh! Drink your fill in high delight,/ And never leave your wine-cup empty in moonlight!/ Heaven has made us talents, we're not made in vain./ A thousand gold coins spent, more will turn up again./ ..."[5] This poembegan with two "Do you not see...?" as rhetorical questions to arouse the attention of the readers, then employed the compact and masculine language to demonstrate a robust and flowing style. Li Bai's unconventionality and boldness were thus artistically protruded between the lines. Especially the images like "the Yellow River", "sea", "chambers", "snow-white hair", "wine-cup", "gold coins", etc became wonderful evidences to show that compact and masculine language is essentially unique and charming. Also, Li Bai's selections of verbial phrases like "come from the sky", "Rushing into the sea", "Drink your fill in high delight", "never leave your wine-cup empty", "made us talents", "turn up again", etc decalred that poetic language should be vigorous and individual. Apart fromLi Bai's "Invitation to Wine", Du Fu's "My Cottage Unroofed by Autumn Gales" can be another reference-"In the eighth moon the autumn gales furiously howl;/ They roll up three layers of straw from my thatched bower./ The straw flies across the river and spreads in shower,/ Some hanging knotted on the tops of trees that tower, / Some swirling down and sinking into water foul./ ..."[5] In this poem, Du Fu's language was concise and vivid though his feelings were extremely complex at that time. Particularly, the images like "autumn gales", "layers of straw", "tops of trees", etc and the verbial phrases like "furiously howl", "roll up", "swirling down", etc had perfectly demonstrated his masculine portrayals of the nature and the human world.

Both Highlight the Musical Rythmes While Pouring Out Emotions. Ezra Pound ever claimed in his Imagist Manifesto that "as regarding rhythm: to compose in sequence of the musical phrase, not in sequence of the metronome'[3]. Pound's intention was that Imagists should make good use of musical rythmes, yet not abuse them. So to speak, poets' true emotions and understandings of the world were the desired destinations. Based upon this insight, American Imagists experimented to compose their poems that could mirror their real 
identities and personalities. F. S. Flint's "Trees" will be a good example-"Elm trees/ and the leaf the boy in me hated/ long ago — / rough and sandy./ Poplars/ and their leaves,/ tender, smooth to the fingers,/ and a secret in their smell/ I have forgotten...'[4] In this poem, Flint combined his knowingness of the trees with his individual speculations. To do so, he integrated the assonance and consonance into a whole being, making the musical rythmes happen between "Elm trees", "the leaf the boy in me", "rough and sandy", "a secret in their smell", etc. Virtually, Flint intended to take the advantage of the musical rythmes to express his emotions and his style turned out to be flexible. D. H. Lawrence's "Ballad of Another Ophelia" is another instance-"Oh, the green glimmer of apples in the orchard,/ Lamps in a wash of rain,/ Oh, the wet walk of my brown hen through the stackyard,/Oh, tears on the window pane!/ ...'[4] Obviously, Lawrence's emotions were revealed through the musical rythmes going between "green glimmer", "wet walk", "brown hen", "window pane", etc.

In Chinese Tang Poetry, Tang Poets had actually expereinced strict training in employing musical rythmes when composing poetic lines. Generally, Tang Poets developed their own particular strategies and policies of using meters and rhythmic patterns, which was, to some extent, a typical reflection of their own cultures and beliefs. Here is an example about Wang Wei's 'Thinking of My Brothers on Mountain-climbing Day"-“Alone, a lonely stranger in a foreign land,/ I doubly pine for kinsfolk on a holiday./ I know my brothers would, with godwood spray in hand, Climb the mountain and think of me so far away." In this poem, Wang Wei poured out his unique emotions by virtue of the musical rythmes between the meters of "Mountain-climbing Day", "Alone, a lonely stranger", "pine for kinsfolk", "think of me so far away", etc. Besides, He Zhizhang's "Home-coming”, He Zhizhang's “The Willow Tree”, Wang Zhihuan's “Out of the Great Wall”, Wang Han's "Starting for the Front", etc all belong to the examples of this sort[5].

\section{Summary}

In conclusion, American Imagist Poetry and Chinese Tang Poetry are unique beings in their respective cultures. Also, they are undoubtedly the texts that share the basic artistic qualities and features. In the domain of intertextuality proposed by Julia Kristeva, both American Imagist Poetry and Chinese Tang Poetry have abundant themes to intermingle or refer to. In essence, they are communicative, echoing and interactive, one typical example of which is about their images. As for the portrayals of images, corresponding strategies are unvoidable. The integrated strategies of composing images in the two poetries can be viewed through the facts that both emphasize the direct and objective treatment of the images, both advocate the compact and masculine language, and both highlight the musical rythmes while pouring out emotions.

\section{Acknowledgement}

This research was financially supported by Shaanxi Social Science Fund(2014J11) and 2016 Shaanxi Normal University Research Fund of “Teachers' Teaching Innovation and Practice”(JSJX2016Y007).

\section{References}

[1] J. Kristeva, Word, dialogue and novel, in: T. moi (ed.), The Kristeva Reader, Blackwell Publisher Ltd., Oxford, 1986, pp. 36-37.

[2] T. Samoyault, L'Intertextualité: Mémoire de la Littérature, Nanthan, Coll, Paris, 2001, pp. 71-79.

[3] K. L. Goodwin, The Influence of Ezra Pound, Oxford Unviersity Press, London, 1966, pp. 11-12.

[4] Information on http://www.gutenberg.org

[5] Y. C. Xu, Tang Poetry, Vols 1-2, Dolphin Books, Beijing, 2013. 